\title{
Límites urbanos y sexuales: una sentencia como muestra de selectividad
}

\author{
Por Zygielman Tale
}

\section{Resumen}

En este ensayo nos proponemos investigar, a raíz de la sentencia que se dio a conocer por el Tribunal Criminal Oral $\mathrm{N}^{\circ} 1$ en el que agravan la pena a una trabajadora de la Zona Roja por el hecho de ser migrante, aquellos elementos que se ponen en juego a la hora de interrogarnos cómo fue posible un fallo de tales características, al cual consideramos, no como un acto carente de subjetividad sin finalidad política, sino como un producto sociohistórico inmiscuido de ideología y de discurso.

Para intentar desentrañar a la pregunta y a los diversos factores que confluyen a la hora de analizar la problemática, tomaremos diferentes ejes.

Primeramente, lo referido a criminalización, selectividad y vulnerabilidad para entender cómo operan dichas categorías en las vivencias que tienen las trabajadoras sexuales todos los días y de ese modo intentar dar cuenta del funcionamiento del poder punitivo en dicho contexto.

Luego analizaremos el control que recae sobre estos sujetos; desde dos perspectivas que se entrelazan; primeramente, en lo que hace al entramado del espacio público, ya que estos sujetos irrumpen en la escena de una ciudad diseñada acorde a ciertos postulados y crean una resistencia al modo de habitar esa ciudad; y segundo como se intenta disciplinar a estos sujetos con identidades no masculinas cuando salen a la ciudad mostrando otras formas posibles de habitar el género.

Por ultimo haremos un análisis crítico del agravante por nacionalidad que plantea el fallo, desnudando la verdadera intencionalidad que subyace al mismo como acto político regulativo de la sexualidad en el espacio público.

Palabras claves: espacio público, migrantes, género, criminalización.

\section{Introducción}

\section{La selectividad del poder punitivo sobre el colectivo trans.}

Comenzaremos hablando de la criminalización secundaria, y en particular del modo que tiene de expresarse en manos de las agencias policiales, cuando se proyectan en 
la zona roja de la ciudad de La Plata. Utilizaremos esta categoría que consideramos apropiada para dar cuenta de la situación que vivencian las trabajadoras sexuales ${ }^{1} s$

La criminalización secundaria implica que las agencias policiales eligen del total de la población, según estereotipos basados en prejuicios racistas, sexistas, xenófobos, el número de futuros prisionizados, los cuales serán llevados a la justicia para que esta resuelva cuanto poder punitivo va a contener. La criminalización secundaria alcanza a los individuos que cargan con estereotipos y cometen hechos poco groseros y sofisticados y no al total de la población como se cree, porque de esa forma sería inabarcable para las agencias policiales (Zaffaroni 2005). Además, por su preparación, podemos pensar que estas agencias están destinadas a perseguir hechos simples.

En el fallo que decidimos analizar se condena a una persona por el hecho de comercializar sustancia en una dosis mínima, lo que da cuenta que el accionar policial solo pudo arremeter contra el último eslabón de esa cadena de comercialización (hecho poco grosero) y no contra el narcotráfico a gran escala. Podemos deducir de esta forma que el interés que se busca es disciplinante, en violación al artículo $19 \mathrm{CN}$ (acciones privadas de los hombres) y no encuentra fundamento en una grave afectación al bien jurídico.

No podemos perder de vista que la victimización también es selectiva, cuando estas personas provienen de clases sociales bajas, es racista, etaria, de género y prejuiciosa. Podríamos pensar que en este caso y dada la múltiple vulnerabilidad que las atraviesa, estas personas también estarían dentro del catálogo de posibles víctimas; esto es así debido a su situación de trabajadoras sexuales, por trans y más aún en el caso de ser migrantes lo que muchas veces imposibilita su acceso a la justicia para denunciar hechos delictivos contra ellas.

Existiría una doble selectividad del poder punitivo; por estereotipo, tanto al momento de ser sujetos pasibles de criminalización, como al momento de ser víctimas de delitos.

Ya en el año 2014 El Observatorio De Violencia De Genero De La Defensoría Del Pueblo, dio a conocer un documento de política de inclusión para colectivo Trans y travesti, donde se expresaba la preocupación por las violaciones a derechos humanos que sufre este colectivo en la zona roja de la ciudad de la plata, y expresaban la constitución de un documento público y mesas de trabajo para avanzar en mecanismos de protección ${ }^{2}$.

1 En este trabajo no ahondaremos en las discusiones binómicas entre abolicionismo y reglamentarismo, sino que tomaremos el término trabajadoras sexuales porque de los testimonios del fallo, emerge que ellas se reconocen de ese modo.

2 "Las mesas de trabajo han sido convocadas a partir de la vulneración de derechos producida por parte de los/las funcionarios/as judiciales, estatales, agentes municipales y el personal policial a partir de detenciones masivas de personas trans y travestis en la denominada "Zona Roja" de la ciudad de la Plata. Esta vulneración de derechos se ha puesto de manifestó, además, en los allanamientos realizados en sus lugares de residencia. A partir de lo acordado en las mesas de trabajo, las organizaciones y el OVG han producido este documento de carácter público." Documento políticas de inclusión y reconocimiento para el colectivo trans y travestis, del Observatorio de Violencia de Género de la Defensoría del Pueblo de la Provincia de Buenos Aires. Año: Mayo, 2014. Recuperado de http://www.defensorba.org.ar/ovg/pdfs/Documento-Trans.pdf 


\section{El género, lo público y lo habitable como fronteras urbano-sexuales}

Nos interesa preguntarnos por los diferentes factores que confluyen a la hora de analizar la práctica concreta de la criminalización que recae sobre las trabajadoras sexuales.

Advertimos que el relato social puesto en juego, está constituido por un imaginario colectivo que construye determinadas formas de ser sujeto y niega al mismo tiempo otras, que invisibiliza y obstruye formas de sentir y habitar la calle; que reniega de sujetos posibles, alternos, que hace y deshace en diferentes momentos históricos lo que es válido para ser considerado "ciudadano", lo valido y lo inválido a la hora de sentir y hacer.

La normativización construye subjetividad y la ley se cimienta así no solo como un factor de lo exterior, sino en lo más interior de cada uno regulando propio cuerpo y el ajeno, entendido este "no como un «ser» sino un límite variable, una superficie cuya permeabilidad está políticamente regulada.” (Butler, 2007: pág. 271)

Los sujetos que irrumpen como actores principales en este ejercicio de poder territorial y fronterizo, son los vecinos, acompañados por la agencia policial y judicial.

Una investigación llevada a cabo por Sabsay Leticia; toma a los vecinos como aquellos sujetos que encarnan un supuesto límite socio-imaginario en la frontera espacial:

De este modo el constructo social "los vecinos" al confrontarse con su otro, "las travestis", "las prostitutas", indica la presencia de una frontera que le asigna un lugar en el territorio a cada sujeto. Las características del vecino, aquel que pertenece al barrio, a la ciudad, funcionaron como marcadores territoriales que espacializan la pertenencia imaginaria a la comunidad, le da expresión espacial a la figura más abstracta del ciudadano ideal, "los vecinos" son conscientes de que las imágenes del trabajo sexual callejero podrían desestabilizar esta sexualidad normativa (Sabsay 2011:151)

De esta forma los vecinos como uno de los actores principales del disiplinamiento espacial junto a la agencia policial y judicial, conforman un entramado que da lugar al castigo de aquellas trabajadoras que desafían la normalización ${ }^{3}$, entendida como aquel control que impone formas hegemónicas de ser, en este caso formas normativas de organizar la sexualidad.

Para aquellos cuerpos que no se corresponden con el binomio hombre/mujer (creado como una bipolaridad regulativa de la sexualidad) se pone en funcionamiento un control legal y policial, que no permite a estas personas habitar la ciudad con la misma legitimidad de quienes si cumplen la norma heterosexual.

\footnotetext{
3 Según ideas de Foucault "en el momento mismo en que se creía, en que los revolucionarios franceses, por ejemplo, creían llegar a una sociedad de derecho, resulta que paso algo que yo trato justamente de analizar, algo que abrió las puertas a la sociedad de la norma, la salud, la medicina, la normalización que es nuestro modo esencial de funcionamiento en la actualidad." En Michel Foucault. El poder, una bestia magnífica sobre el poder, la prisión y la vida. (Año:2012 Ed: siglo XXI editores, pág. 34
} 
Dado justamente que ese espacio habitable tanto físico como subjetivo se afirma binomico y heterosexual ${ }^{4}$.

Estos Cuerpos se imponen como una amenaza a un supuesto orden instaurado, de una ciudad planeada. En este caso la ciudad de La Plata fue una ciudad planificada, bajo las teorías del urbanismo basadas en los postulados higienistas y funcionales. La ciudad concepto, implica que los territorios son lugares de confrontación y disputa de poder.

En fin, la organización funcionalista, al privilegiar el progreso (el tiempo), hace olvidar su condición de posibilidad, el espacio mismo, que se vuelve lo impensado de una tecnología científica y política. Así funciona la Ciudad- concepto, lugar de transformaciones y de apropiaciones, objeto de intervenciones, pero sujeto sin cesar enriquecido con nuevos atributos: es al mismo tiempo la maquinaria y el héroe de la modernidad." "El lenguaje del poder "se urbaniza", pero la ciudad está a merced de los movimientos contradictorios que se compensan y combinan fuera del poder panóptico. La Ciudad se convierte en el tema dominante de los legendarios políticos, pero ya no es un campo de operaciones programadas y controladas. Bajo los discursos que la ideologizan, proliferan los ardides y las combinaciones de poderes sin identidad legible, sin asideros, sin transparencia racional: imposibles de manejar (De Certau 2000, 107).

Podemos concluir que las trabajadoras de la zona roja, arremeten contra un territorio que no las pensó y desafían sus límites tanto espaciales como sexuales. En este sentido "Las ideas acerca de alejar, purificar, delimitar y sancionar transgresiones tienen como función principal establecer un sistema sobre una experiencia inherentemente desordenada. Únicamente al ampliar la diferencia entre dentro y fuera, arriba y abajo, hombre y mujer, con y contra, se crea una semejanza de orden”. (Douglas, en Butler, 2007: 258) Tanto el cuerpo, como el espacio público en el que este cuerpo se hace sujeto, se hace carne, son lugares que per-se se piensan estáticos y a los cuales las trabajadoras desafían, al interpelar la matriz heterosexual predominante y al demostrar que son posibles otras formas de habitar ese territorio fuera del supuesto orden normalizador.

El espacio territorial y social posee resistencias, por ello no debe resultar extraño, la constante puja que existe entre la zona que le son asignadas a las trabajadoras por parte del poder político y los lugares que las mismas consideran peligrosos para su trabajo, por ser zonas que se encuentran por fuera del casco urbano ${ }^{5}$

\footnotetext{
4 "La heterosexualización del deseo exige e instaura la producción de oposiciones discretas y asimétricas entre «femenino» $\mathrm{y}$ «masculino», entendidos estos conceptos como atributos que designan «hombre» $\mathrm{y}$ «mujer». La matriz cultural -mediante la cual se ha hecho inteligible la identidad de género- exige que algunos tipos de «identidades» no puedan «existir»: aquellas en las que el género no es consecuencia del sexo y otras en las que las prácticas del deseo no son «consecuencia» ni del sexo ni del género. En este contexto, «consecuencia» es una relación política de vinculación creada por las leyes culturales, las cuales determinan y reglamentan la forma y el significado de la sexualidad.” Butler, Judith. El género en disputa. (Buenos Aires: Editorial Paidós, 2007, pág. 72)

${ }^{5}$ En la ciudad de la plata el permanente conflicto tiene relación con determinar en qué territorio se delimita para la zona roja, en el último tiempo se quiere desde el poder político llevar la misma al bosque. De esta problemática dan cuenta los siguientes artículos periodísticos http://www.eldia.com/nota/2016-2-26- reflotan-proyecto-para-mudar-la-zona-roja-al-corazon-delbosque http://www.eldia.com/nota/2016-3-5-de-espacio-verde-y-cultural-a-zona-roja
} 
Así se establece una política de control territorial que reafirma la norma heterosexual y conlleva la invisibilización de los cuerpos que molestan y se presumen desechables; generándose de este modo ciudadanos "legítimos" con derecho pleno al ejercicio de lo público y aquellos para los que se reserva solo una porción de ese espacio.

\section{El fallo: un análisis crítico}

Trataremos algunas aproximaciones de la sentencia para dar cuenta de cómo se expresan en este pronunciamiento todas las cuestiones que hemos desarrollado, el modo de funcionamiento de la criminalización y el control sexual y espacial que recae sobre los cuerpos que no acatan la norma heterosexual

En principio como muestra concreta de selectividad y subjetividad heterosexual tomaremos el relato del testigo policial. ${ }^{6}$ De su declaración podemos inferir que existe una clara directiva de persecución contra las trabajadoras de la zona roja, en una deliberada violación al principio de igualdad ante la ley (art $18 \mathrm{CN}$ ) ya que la orden era vigilar y requisar a un grupo determinado de personas por el solo hecho de formar parte del colectivo Trans (selectividad conforme a estereotipo). Además, contraria al espíritu de la ley de identidad de género ${ }^{7}$, ya que no identificaban allí personas con identidad de género femenina, sino que encontraban "hombres vistiendo ropa de mujer" ${ }^{8}$ No podemos perder de vista que la agencia policial como

\footnotetext{
6 Testigo policial: "Que eran pocos efectivos y que siempre trabajaba con los mismos, algunos eran novatos en este tipo de procedimientos. Que la Fiscalía les pedía habitualidad, que con un mínimo de dos procedimientos a la misma persona ya era habitual" ... "Que ellos, como personal policial, vigilaban y esperaban alguna maniobra rara. "Que ha realizado tareas de inteligencia en autos, en moto, por la zona roja. Que no recuerda a la persona imputada, que ha revisado a muchas personas." (Fallo del tribunal Oral Criminal $N^{\circ} 1$ de la Ciudad de La Plata, 10 de mayo de 2016)

7 "Exhortar a la Dirección Nacional de Migraciones, por ante el área que corresponda, -para lo cual, ordeno librar inmediato oficio y copia certificada de la presente sentencia-, que constate bajo qué circunstancias legales - de admisión y permanencia en el país- se encuentran los ciudadanos extranjeros que ofrecen servicios como travestis en la denominada Zona Roja de la Ciudad de La Plata; esto, ante la denuncia que hiciera, en estos obrados, personal policial, en tanto y en cuanto resultaba difícil su identificación por no tener documentos que acrediten su identidad, y por camuflarse en una actividad no prohibida, la posible comisión de delitos graves como el aquí tratado."
}

IV- Exhortar al sr. intendente municipal de la ciudad de la plata, Don Julio Garro -para lo cual ordeno se libre oficio y copia certificada de la presente sentencia- a fin de que tome las medidas que considere necesarias; ante la multiplicidad de delitos que, como en la presente, se vienen suscitando de la denominada Zona Roja de la Ciudad de La Plata; y de respuesta a los constantes reclamos de los vecinos, por las molestias que se les causan

ARTICULO $2^{\circ}$ - Definición. Se entiende por identidad de género a la vivencia interna e individual del género tal como cada persona la siente, la cual puede corresponder o no con el sexo asignado al momento del nacimiento, incluyendo la vivencia personal del cuerpo. Esto puede involucrar la modificación de la apariencia o la función corporal a través de medios farmacológicos, quirúrgicos o de otra índole, siempre que ello sea libremente escogido. También incluye otras expresiones de género, como la vestimenta, el modo de hablar y los modales. ARTICULO $1^{\circ}$ - Derecho a la identidad de género. Toda persona tiene derecho: $\mathrm{Al}$ reconocimiento de su identidad de género; $\mathrm{Al}$ libre desarrollo de su persona conforme a su identidad de género; A ser tratada de acuerdo con su identidad de género y, en particular, a ser identificada de ese modo en los instrumentos que acreditan su identidad respecto de el/los nombre/s de pila, imagen y sexo con los que allí es registrada.

8 Soportar, la venta de estupefacientes; los constantes desfiles indecorosos; el permanente ir y venir de compradores de dudosa reputación y gente de mal vivir; las reiteradas reyertas que se provocan; los 
parte del estado está obligado por la ley a respetar en el procedimiento la identidad de género de esa persona. Y que no basta con ser requisado por policial femenino para agotar lo que la norma indica.

\section{Agravantes por Nacionalidad}

La fiscalía pide que se agrave la pena, fundada en diferentes motivos entre ellos la de ser de nacionalidad extranjera, en este caso peruana. Expresa la agravante Condición de ser un extranjero toda vez que menospreció el país que le dio cobijo. Esta agravante se funda en un derecho penal de autor, propio de los estados totalitarios que desconoce principio de acto y relativiza la igualdad ante la ley (Art. $18 \mathrm{CN}$ ).

Entre los argumentos se apela a una supuesta moral universal que invoca el fallo como aquella "de la que nadie esta privado", propio de un discurso que se emparenta con el positivismo criminológico de principios del siglo XX; cuyo exponente en nuestro país fue Eusebio Gómez y la conocida obra "la mala vida en Buenos Aires". Los argumentos de la sentencia son propios de un derecho penal de autor, lo expresa claramente cuando se refiere a "gente de mal vivir, constantes desfiles indecorosos, el permanente ir y venir de compradores de dudosa reputación" asocia delito con inmigración y prostitución.

El juez al agravar la pena por el hecho de que la persona es peruana esta deliberadamente juzgando a la misma por ser nacida en Perú, nuestro derecho penal liberal solo juzga art $19 \mathrm{CN}$ (los actos) art $18 \mathrm{CN}$ (hecho del proceso) por ende, nada de relevante puede significar para nuestro derecho penal ser inmigrante, solo podría ser entendida en su beneficio dada su mayor vulnerabilidad (principio in bonam partem)

El llamado derecho penal de autor- renuncia a la pretensión de que el tipo legal mismo capte personalidades y no actos, prohíba ser de cierto modo, en lugar de prohibir ciertas acciones conflictivas. En consecuencia, la racionalización de ciertos tipos de autor (o de enemigo) es el signo más burdo de claudicación del derecho penal, su inversión y puesta al servicio del estado de policía (Zaffaroni, 2005:343).

No podemos perder de vista la finalidad política que subyace a este fallo, cuando en su voto, el juez exhorta a migraciones y a la municipalidad a relevar la situación de todas las inmigrantes que se encentran en la zona roja. Dilucidamos así el cauce formal de una política de persecución para las trabajadoras y una sanción que busca ser ejemplificadora para este colectivo.

\section{Conclusión}

El poder punitivo desde la Edad Media hasta nuestros días tiene el mismo funcionamiento: evoca una emergencia y crear un enemigo. En un Estado

procedimientos policiales; escenas de sexo en el umbral de la casa; ruidos que provocan sobresaltos y gritos en horas reservadas al descanso; entre otras circunstancias, son a no dudar, molestias que ningún habitante de la Nación, ni de la Ciudad de La Plata, está obligado a tolerar, ni privado de su derecho al mantenimiento de la moral y las buenas costumbres." (Fallo del tribunal Oral Criminal № 1 de la Ciudad de La Plata, 10 de mayo de 2016) 
constitucional de derecho, en el que el derecho penal es la última ratio del Estado, las garantías del imputado/a forman parte del dato de contra selectividad que debe oponérsele, para dejar pasar la menor cantidad de poder punitivo.

Esta sentencia como adelantamos en el comienzo de este trabajo, no es ingenua ni imparcial, como intenta aparecer, está cargado de contenido moral propio, de tinte positivista, que agravan la pena a los sujetos por la mera conducción de la vida, como el hecho de ser extranjera y trabajadora sexual y no por lesionar un bien jurídico.

También concebimos que la criminalización secundaria ejercida por los vecinos y la agencia policial, luego continuada por el juez, se expresa y cimienta en la construcción de la subjetividad heterosexual, que ordena y regula las formas de existir en el espacio público, al aparecer estos cuerpos como disidentes, se los quiere corregir.

Entre los actores intervinientes el relato posiciona a los vecinos, como aquellos legitimados para ejercer los derechos plenos que le competen como ciudadanos, y a las trabajadoras como aquellas que ocupan el territorio de forma ilegal, creando un ideario dicotómico vecinos vs trabajadoras sexuales.

Además, entendemos que el juez apela a argumentos inconstitucionales de derecho penal de autor, que no fortalecen un estado de derecho, sino que hacen crecer un estado de policía, que busca perseguir determinadas personas basándose en discursos que construyen otredades y postulan a estos sujetos como enemigos.

Hemos tratado a lo largo de este trabajo desarmar el entramado, que creemos, fundan a diario el relato sobre las trabajadoras sexuales y posibilitan su criminalización mediante fallos como el que hemos traído para analizar. 


\section{Bibliografía}

Butler, J. (2007). El género en disputa. Editorial Paidós. Buenos Aires.

..m.m. (1997) Lenguaje, Poder e Identidad. Editorial Síntesis. Madrid

DE CERTAU. (1996). La Invención de lo cotidiano. Editor Universidad Iberoamericana. Foucault, M. (2009). Vigilar y castigar. Ediciones Siglo Veintiuno. Buenos Aires.

(2012). El poder, una bestia magnifica sobre el poder, la prisión y la vida. Siglo XXI editores. Buenos Aires.

Congreso de la Nación Argentina. (2012) Ley De Identidad de Género: ley 26.743 publicado boletín oficial. Buenos Aires.

SABSAY, L. (2011). Fronteras Sexuales. Espacio urbano, cuerpos y ciudadanía. Editorial Paidós. Buenos Aires.

VÁSQUEZ HARO, C. ( 2014). Identidades migrantes: El aprendizaje social entre las trans peruanas en La Plata. Las charapas. Buenos Aires.

ZAFFARONI, E. R. (2005). Manual de derecho penal: parte general. Editorial Ediar. Buenos Aires.

(2011). La cuestión criminal. Ed. Planeta. Buenos Aires.

Defensoría del Pueblo de la Provincia de Buenos Aires (2014). Observatorio de Violencia de Género. Políticas de inclusión y reconocimiento para el colectivo trans y travestis. En línea en

http://www.defensorba.org.ar/ovg/pdfs/Documento-Trans.pdf 